\title{
Correction to: Acute liver failure in Still's disease relapse during pregnancy: case report and discussion of a possible trigger role of DILI
}

Giuseppe Marrone ${ }^{1 *}$, Francesco Galati ${ }^{1}$, Marco Biolato ${ }^{1}$, Christopher Oddy ${ }^{2}$, Sara De Carolis ${ }^{3}$, Angelo Zoli ${ }^{4}$ and Antonio Grieco ${ }^{1}$

\section{Correction to: BMC Gastroenterol (2021) 21:317} https://doi.org/10.1186/s12876-021-01878-3

After publication of this article [1], the authors noticed that the name of Christopher Oddy was incorrectly written as Cristopher Oddy.

The original article [1] has been updated.

\section{Author details}

${ }^{1}$ Transplant Hepatology Unit - CEMAD Digestive Disease Center, Fondazione Policlinico Universitario "A. Gemelli" IRCCS, Università Cattolica del Sacro Cuore, Largo A. Gemelli 8, 00168 Rome, Italy. ${ }^{2}$ FY2 Intensive Care Medicine, Epsom and St Helier University Hospitals NHS Trust, Epsom, UK. ${ }^{3}$ Obstetrics and Obstetric Pathology Unit, Fondazione Policlinico Universitario "A. Gemelli" IRCCS, Università Cattolica del Sacro Cuore, Rome, Italy. ${ }^{4}$ Osteo-articular Disease Unit, Fondazione Policlinico Universitario "A. Gemelli"IRCCS, Università Cattolica del Sacro Cuore, Rome, Italy.

Published online: 01 October 2021

\section{Reference}

1. Marrone G, Galati F, Biolato M, et al. Acute liver failure in Still's disease relapse during pregnancy: case report and discussion of a possible trigger role of DILI. BMC Gastroenterol. 2021;21:317. https://doi.org/10.1186/ s12876-021-01878-3.

\section{Publisher's Note}

Springer Nature remains neutral with regard to jurisdictional claims in published maps and institutional affiliations.

The original article can be found online at https://doi.org/10.1186/s12876021-01878-3.

*Correspondence: giuseppe.marrone@policlinicogemelli.it

${ }^{1}$ Transplant Hepatology Unit - CEMAD Digestive Disease Center,

Fondazione Policlinico Universitario "A. Gemelli" IRCCS, Università Cattolica

del Sacro Cuore, Largo A. Gemelli 8, 00168 Rome, Italy

Full list of author information is available at the end of the article

(c) The Author(s) 2021. Open Access This article is licensed under a Creative Commons Attribution 4.0 International License, which permits use, sharing, adaptation, distribution and reproduction in any medium or format, as long as you give appropriate credit to the original author(s) and the source, provide a link to the Creative Commons licence, and indicate if changes were made. The images or other third party material in this article are included in the article's Creative Commons licence, unless indicated otherwise in a credit line to the material. If material is not included in the article's Creative Commons licence and your intended use is not permitted by statutory regulation or exceeds the permitted use, you will need to obtain permission directly from the copyright holder. To view a copy of this licence, visit http://creativecommons.org/licenses/by/4.0/. The Creative Commons Public Domain Dedication waiver (http://creativeco mmons.org/publicdomain/zero/1.0/) applies to the data made available in this article, unless otherwise stated in a credit line to the data. 